\title{
PEMANTAUAN ENERGI DAN PENGIRIMAN DATA KINERJA TRANSFORMATOR MENGGUNAKAN WEB
}

\author{
Galuh Permata ${ }^{1}$, Sabar Setiawidayat ${ }^{2}$, Fachrudin Hunaini ${ }^{3}$ \\ ${ }^{1}$ Fakultas Teknik, Jurusan Teknik Elektro, Universitas Widyagama Malang \\ 2Fakultas Teknik, Jurusan Teknik Elektro, Universitas Widyagama Malang \\ ${ }^{3}$ Fakultas Teknik, Jurusan Teknik Elektro, Universitas Widyagama Malang \\ email: galuhpsw89@gmail.com
}

\begin{abstract}
Abstrak
Kinerja tranformator daya dapat dipengaruhi oleh Total Harmonic Distortion (THD) I dalam hal ini adalah arus harmonisa, suhu dan ketidakseimbangan arus. Kinerja yang dimaksud adalah dapat mengurangi kapasitas daya transformator dan umur. Penelitian ini bertujuan untuk menganalisis kinerja transformator berbasis Energy Monitoring Dan Data Transmitter (EMT) menggunakan web. Berdasarkan hasil pengukuran di lapangan, di ketahui bahwa transformator pada Gardu Tiang Transformator (GTT) KFO84 melebihi pembebanan yang dianjurkan. Hasil analisis membuktikan bahwa semakin besar nilai THD arus maka akan semakin besar penurunan kapasitas daya transformator. Kenaikan suhu tidak mempengaruhi besarnya load losses transformator, dan ketidakseimbangan beban diikuti oleh kenaikan arus netral pada pada tranformator.
\end{abstract}

Kata Kunci:daya transformator, Web,EMT,transformator

\begin{abstract}
Power transformer performance can be influenced by Total Harmonic Distortion (THD) I in this case is harmonic current, temperature and current imbalance. The intended performance is to reduce transformer power capacity and age. This study aims to analyze the performance of transformers based on Energy Monitoring And Data Transmitter (EMT) using the web. Based on the results of measurements in the field, it was known that the transformer at the KF084 Transformer Substation (GTT) exceeded the recommended load. The analysis results prove that the greater the THD value of the current, the greater the decrease in transformer power capacity. The increase in temperature does not affect the amount of transformer load losses, and load imbalance is followed by an increase in neutral current on the transformer.
\end{abstract}

Keywords: Transformer, Web, EMT, Transformer Power 


\section{PENDAHULUAN}

Kemajuan teknologi di bidang perangkat elektronik diantaranya adalah menyebabkan adanya peralatan linier dan non linier. Peralatan non linier dapat menimbulkan harmonisa terhadap jaringan listrik. Adanya gangguan pada arus listrik dapat mengakibatkan kerugian penurunan kapasitas daya, ketidakseimbangan beban dan umur transformator daya. Kinerja transformator dipengaruhi oleh pembebanan, semakin besar beban yang harus disuplai maka arus yang dihasilkan juga semakin besar. Dengan semakin besar arus yang dihasilkan maka daya yang dihasilkan juga semakin besar dan hal tersebut berdampak pada panas yang dihasilkan. Penelitian ini akan membahas tentang kinerja transformator daya. Kinerja transformator daya dinilai dari nilai keandalan dan nilai ketersediaan [1].

Suatu transformator dikatakan mempunyai kinerja yang baik jika efisiensinya tinggi, kandungan harmonisa rendah, temperatur dalam batas normal dan nilai penyusutan transformator daya kecil. Penelitian ini bertujuan untuk menganalisis kinerja transformator berbasis Energy Monitoring Dan Data Transmitter (EMT) menggunakan web.

\section{STUDI PUSTAKA}

\subsection{Transformator}

Transformator merupakan suatu peralatan listrik statis, yang merubah energi listrik dari tingkat tegangan yang satu ke tingkat tegangan yang lain. Adanya alat ini memungkinkan untuk menghasilkan energi listrik pada tegangan yang relatif rendah dan mentransmisikannya pada tegangan tinggi dan arus yang rendah, sehingga akan mengurangi kehilangan tegangan jaringan dan digunakan pada tegangan yang aman [1].

\subsubsection{Ketidakseimbangan Beban}

Yang dimaksud dengan keadaan seimbang beban adalah suatu kondisi yang memenuhi syarat:

- Ketiga vektor arus / tegangan sama besar.

- Ketiga vektor saling membentuk sudut $120^{\circ}$ satu sama lain.

Sedangkan yang dimaksud dengan keadaan tidak seimbang adalah keadaan di mana salah satu atau kedua syarat keadaan seimbang tidak terpenuhi. Kemungkinan keadaan tidak seimbang ada 3 yaitu:

- Ketiga vektor sama besar tetapi tidak membentuk sudut $120^{\circ}$ satu sama lain.

- Ketiga vektor tidak sama besar tetapi membentuk sudut $120^{\circ}$ satu sama lain.

- Ketiga vektor tidak sama besar dan tidak membentuk sudut $120^{\circ}$ satu sama lain $[2]$.

\subsubsection{Penyaluran dan Susut Daya}

Misalnya daya sebesar $\mathrm{P}$ disalurkan melalui suatu saluran dengan penghantar netral. Apabila pada penyaluran daya ini arus-arus fasa dalam keadaan seimbang, maka besarnya daya dapat dinyatakan sebagai berikut:

$$
\mathrm{P}=3 \cdot[V] \cdot[I] \cdot \cos \phi
$$


keterangan:

$\mathrm{P} \quad=$ daya pada ujung kirim

$\mathrm{V} \quad=$ tegangan pada ujung kirim

$\cos \varphi=$ faktor daya

Daya yang sampai ujung terima akan lebih kecil dari $\mathrm{P}$ karena terjadi penyusutan dalam saluran.

Jika [I] adalah besaran arus fasa dalam penyaluran daya sebesar $\mathrm{P}$ pada keadaan seimbang, maka pada penyaluran daya yang sama tetapi dengan keadaan tak seimbang besarnya arus-arus fasa dapat dinyatakan dengan koefisien a, b dan c sebagai berikut:

$$
\begin{aligned}
& {\left[\mathrm{I}_{\mathrm{R}}\right]=a[I]} \\
& {\left[\mathrm{I}_{\mathrm{S}}\right]=b[I]} \\
& {\left[\mathrm{I}_{\mathrm{T}}\right]=c[I]}
\end{aligned}
$$

dengan $I_{R}$, Is dan $I_{T}$ berturut-turut adalah arus di fasa $R, S$ dan $T$.

Bila faktor daya di ketiga fasa dianggap sama walaupun besarnya arus berbeda, besarnya daya yang disalurkan dapat dinyatakan sebagai :

$$
\mathrm{P}=(a+b+c) \cdot[V\} \cdot \cos \phi
$$

Apabila persamaan (21) dan persamaan (22) menyatakan daya yang besarnya sama, maka dari kedua persamaan itu dapat diperoleh persyaratan untuk koefisien $a, b$, dan c yaitu :

$$
a+b+c=3
$$

dimana pada keadaan seimbang, nilai $\mathrm{a}=\mathrm{b}=\mathrm{c}=1$

\subsubsection{Variasi Rugi-Rugi Pembebanan (Load Losses)}

Sekitar 90\% dari load losses yang diukur dengan tes hubung singkat adalah rugi-rugi $I^{2} \mathrm{R}$ pada gulungan. Berbeda dengan kuadrat Arus dan juga suhu gulungan [3].

$$
\text { load losses }=(p u \text { loading })^{2} x \text { load losses } x\left(\frac{F+T_{o p}}{F+T_{r e f}}\right)
$$

Keterangan:

$\mathrm{F}=$ koefisien suhu $=234.5$ untuk tembaga dan 227 untuk aluminium

Tref $=75^{\circ} \mathrm{C}$

\subsubsection{Harmonisa}

Harmonisa adalah gangguan yang terjadi dalam sistem distribusi tenaga listrik yang disebabkan adanya distorsi gelombang arus dan tegangan. Distorsi gelombang 
arus dan tegangan ini disebabkan adanya pembentukan gelombang-gelombang dengan frekuensi kelipatan bulat dari frekuensi fundamentalnya.

Harmonisa dapat muncul akibat adanya beban - beban non linier yang terhubung ke sistem distribusi. Beban non liner ini umumnya adalah peralatan elektronik yang di dalamnya banyak terdapat komponen semi konduktor, yang dalam proses kerjanya berlaku sebagai saklar yang bekerja pada setiap siklus gelombang dari sumber tegangan. Beberapa contoh beban non liner antara lain : variable speed drive, komputer, printer, lampu fluorescent yang menggunakan elektronik ballast [4].

\subsection{Energy Monitoring Dan Data Transmitter (EMT)}

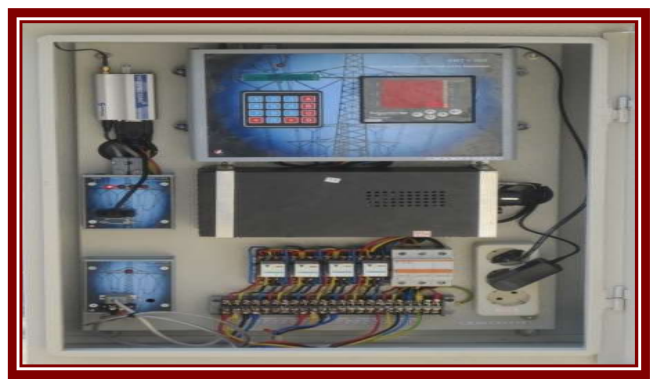

\section{Gambar 2.1. EMT (Energy monitoring\&data transmitter)}

Pemasangan peralatan ini dilakukan pada gardu tiang transformator (GTT), dan peralatan ini berfungsi untuk melakukan pengukuran dalam periodisasi tertentu untuk memperoleh besaran-besaran Power Quality (arus, tegangan, power factor, daya, THD, dan energy).

Selanjutnya data pengukuran tersebut disimpan dan kemudian di kirim ke server melalui pesan singkat (SMS) GSM.

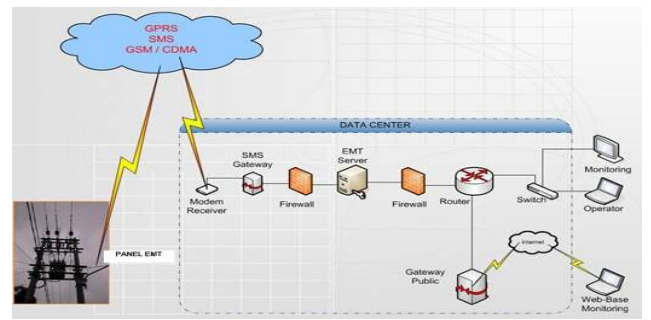

Sumber : (http://documents.tips/documents/gardutransformator-tiang.html).

Gambar 2.2. Diagram Blok Proses Penerimaan Data

\subsection{WEB}

\subsubsection{Bahasa pemrogaman}

Hypertext Preprocessor (PHP) adalah bahasa pemrograman script server-side yang didesain untuk pengembangan web. Selain itu, PHP juga bisa digunakan sebagai bahasa pemrograman umum (wikipedia). PHP di kembangkan pada tahun 1995 oleh Rasmus Lerdorf, dan sekarang dikelola oleh The PHP Group. Situs resmi PHP 
beralamat di http://www.php.net.PHP disebut bahasa pemrograman server side karena PHP diproses pada komputer server. Hal ini berbeda dibandingkan dengan bahasa pemrograman client-side seperti JavaScript yang diproses pada web browser (client) (www.duniailkom.com).

\subsubsection{Server microsoft azure}

Microsoft azure adalah media penyimpanan data yang berfungsi sama dengan penyimpanan data seperti biasa, yang membedakan adalah microsoft azure ini dengan media penyimpanan data dengan bentuk fisik adalah layanan yang diberikan oleh meicrosoft dimana kita dapat menyimpan data secara aman dicloud, yang artinya data anda tidak disimpan pada media penyimpanan seperti Harddisk atau storage fisik laninya. Anda tidak hanya bisa menyimpan data pada layanan ini, ada beberapa feature seperti menjalankan berbagai aplikasi dari berbagai platform pada tempat penyimpanan, yang membedakan azure dengan vendor penyedia layanan berbasis cloud computing lainnya. Beberapa feature aplikasi yang bisa dijalankan diantaranya seperti bahasa pemrograman .NET, JAVA dan juga PHP.

\section{METODE}

\subsection{Alur Kerja Metode Penelitian (Flowchart)}

Alur kerja menggambarkan secara global langkah - langkah yang akan dilakukan dalam proses pengambilan data, dimulai dari proses survey lapangan dilanjutkan pemasangan alat ukur, pengukuran dan pengambilan data, kemudian proses analisis dan pengambilan keputusan.

Dari uraian alur kerja dapat digambarkan dalam flowchart berikut ini

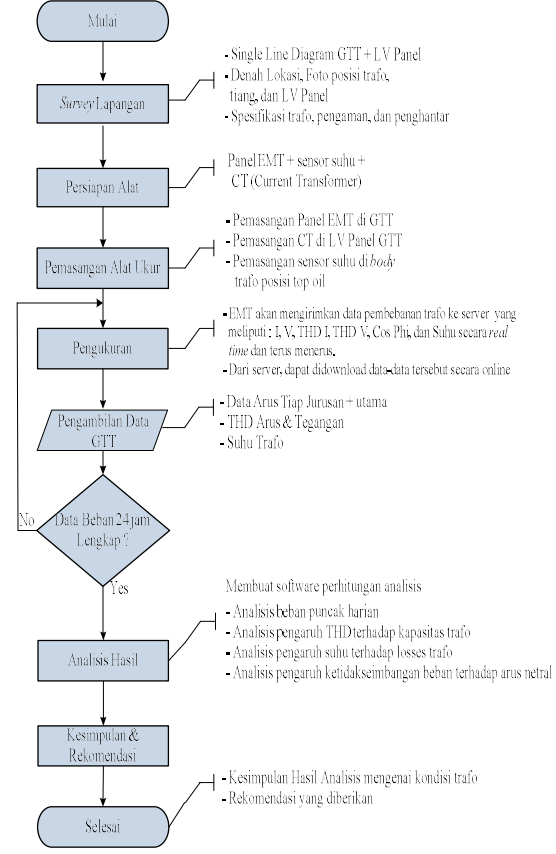

Gambar 3.1. Flowchart Analisis Permbebanan Gardu Transformator Tiang KF 084. 


\subsection{Pembuatan dan Perancangan Software}

Software disini digunakan sebagai alat bantu untuk melakukan perhitungan dan analisis secara cepat dan akurat. Perancangan software ini meliputi perhitungan pembebanan harian, kapasitas maksimal transformator akibat adanya harmonic, perhitungan Load Losses akibat kenaikan suhu transformator, perhitungan unbalance serta perencanaan untuk penyeimbangan beban.

Adapun diagram blok perancangan software ini adalah sebagai berikut:

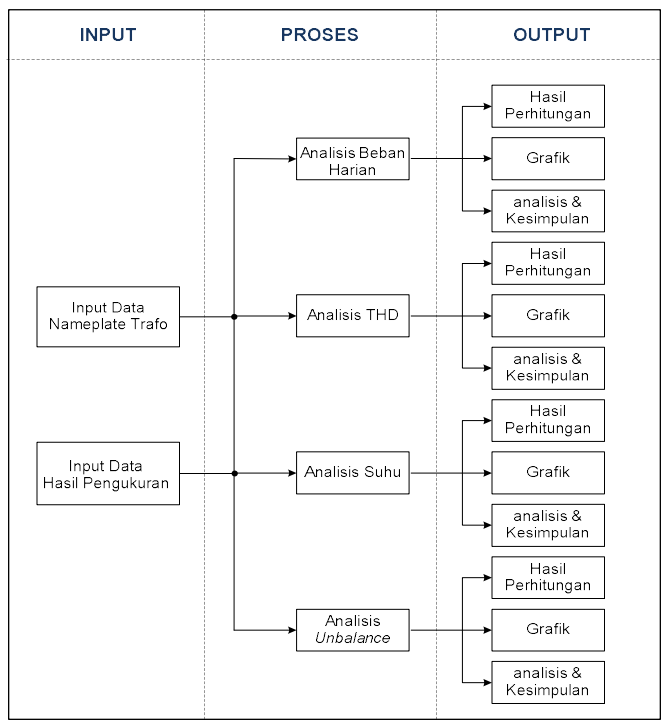

Gambar 3.2. Diagram Blok Software Analisis Permbebanan Transformator GTT

\section{HASIL DAN PEMBAHASAN}

\subsection{Perhitungan software}

Setelah operator berhasil log in dan memasukkan data pada web, maka selanjutnya menampilkan hasil analisis transformator dan grafik hasil analisis.

GENERAL TABLE

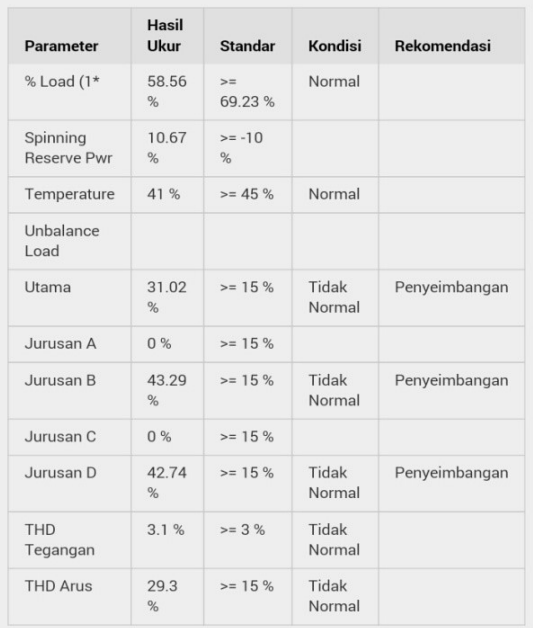

Gambar 4.1 Tampilan Hasil Analisis pengukuran 
General table menampilkan data hasil analisis transformator secara keseluruhan berdasarkan data pengukuran dari pembacaan alat EMT dalam waktu 24 jam. Dalam menu general table akan menganalisis mengenai prosentase pembebanan transformator saat beban puncak. Dari hasil pengukuran pada transformator KF084 didapatkan load atau beban puncak sebesar $58.56 \%$. Transformator tersebut masih dalam keadaan normal dan masih bisa dibebani atau spinning reserve power sebesar 10.67\%. Temperatur 41\% dengan kondisi normal. Unbalance load utama $31.02 \%$ tidak normal perlu dilakukan penyeimbangan. Penyeimbangan dilakukan di arus jurusan yaitu dijurusan $B$ dengan unbalance $43 \%$ dan di jurusan $D$ unbalance 42.74\%. THD Tegangan 3.1\% dan THD arus 29.3\% kondisi tidak normal.

\subsection{Grafik beban harian}

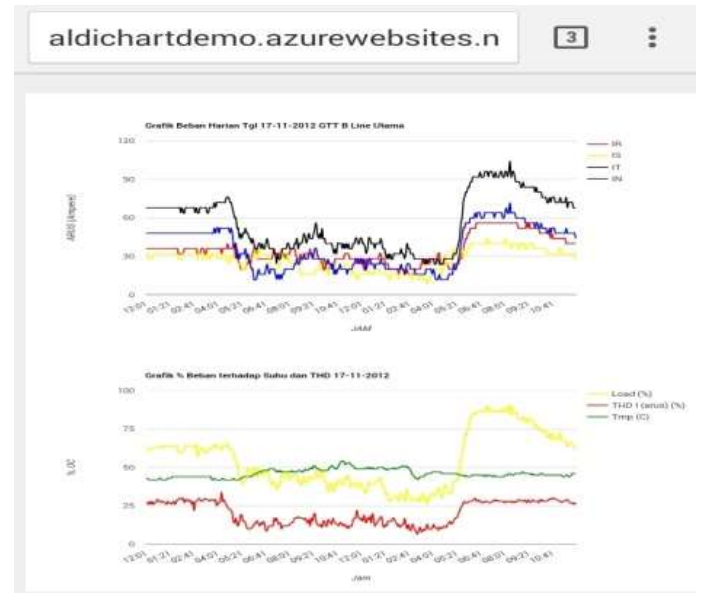

Gambar 4.2 Grafik Beban Harian Line Utama dan Grafik Beban Terhadap Suhu dan THD

\subsection{Analisis Transformator secara manual}

\subsubsection{Analisis pengaruh THD arus terhadap kapasitas daya transformator}

Tabel 4.1 Data THD arus terhadap kapasitas daya transformator

\begin{tabular}{|c|c|c|c|}
\hline $\begin{array}{c}\text { Waktu } \\
\text { beban } \\
\text { puncak }\end{array}$ & $\begin{array}{c}\text { Load } \\
(\%)\end{array}$ & $\begin{array}{c}\text { THD } \\
\text { I (\%) }\end{array}$ & $\begin{array}{c}\text { Pembebanan } \\
\text { Yang di } \\
\text { perbolehkan } \\
\text { (KVA) }\end{array}$ \\
\hline $\begin{array}{c}14 / 11 / 2014 \\
19: 05\end{array}$ & 93,24 & 26,70 & 31,57 \\
\hline $\begin{array}{c}15 / 11 / 2014 \\
20: 17\end{array}$ & 91,63 & 28,90 & 31,03 \\
\hline $\begin{array}{c}16 / 11 / 2014 \\
18: 57\end{array}$ & 90,51 & 25,20 & 31,95 \\
\hline $\begin{array}{c}17 / 11 / 2014 \\
19: 27\end{array}$ & 88,75 & 30,30 & 30,7 \\
\hline $\begin{array}{c}18 / 11 / 2014 \\
18: 59\end{array}$ & 75,90 & 24,60 & 32,1 \\
\hline
\end{tabular}


Berdasarkan tabel 4.1 bahwa THD arus melebihi standart yang telah di tentukan. THD arus terbesar terjadi pada pengukuran $17 / 11 / 2014$ sebesar $30,30 \%$ dan penurunan kapasitas daya transformator terbesar terjadi pada pengukuran $17 / 11 / 2014$ pula sebesar 30,7 Kva.

Pengaruh THD Arus Terhadap Daya Transformator

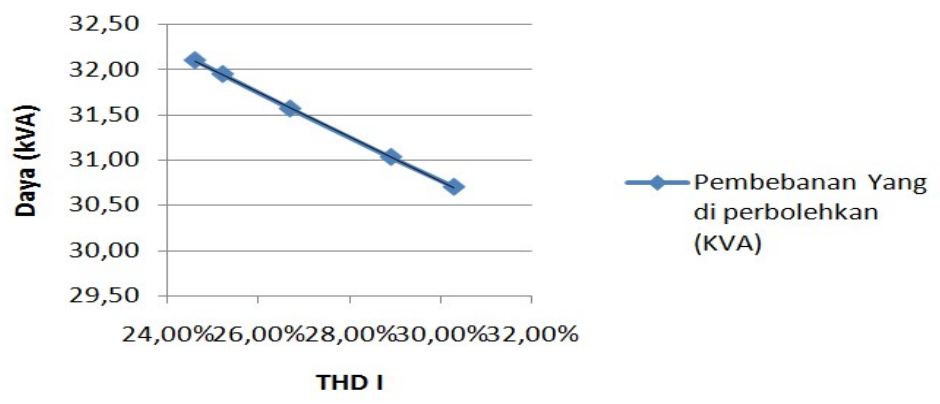

\section{Gambar 4.3 Grafik Pengaruh THD Arus Terhadap Daya Transformator}

Setelah dilakukan analisis THD arus dapat dilihat pada Gambar 4.3 dapat disimpulkan bahwa semakin besar nilai THD arus maka akan semakin besar penurunan kapasitas daya transformator.

\subsubsection{Uji koefisien determinasi $\left(R^{2}\right)$}

Tabel 4.4 koefisiensi determinasi pengaruh THD arus terhadap kapasitas daya transformator.

Coefficients $^{\mathrm{a}}$

\begin{tabular}{|c|c|c|c|c|c|c|c|c|c|}
\hline \multirow[b]{2}{*}{ Model } & & \multicolumn{2}{|c|}{ Unstandardized Coefficient's } & \multirow{2}{*}{$\begin{array}{c}\begin{array}{c}\text { Standardized } \\
\text { Coefficients }\end{array} \\
\text { Beta }\end{array}$} & \multirow[b]{2}{*}{1} & \multirow[b]{2}{*}{ Sig. } & \multicolumn{3}{|c|}{ Correlations } \\
\hline & & $B$ & Std. Error & & & & Zero-orderer & Partial & Palt \\
\hline & (Constant) & 38.151 & .046 & & 821.194 & .000 & & & \\
\hline & THD & .246 & .002 & 1.000 & .144 .266 & .000 & .1 .000 & 1.000 & .1 .000 \\
\hline
\end{tabular}

a. Dependent Variable: Pembetbanan

$$
\mathrm{R}^{2}=\beta \times \text { Zero-order }=-1,000 \times-1,000=1
$$

Koefisien determinasi $\left(\mathrm{R}^{2}\right)$ THD arus 1,000 yang berarti bahwa pengaruh THD arus terhadap kapasitas daya transformator 100\% . Dengan kata lain, variabel THD arus yang dapat diterangkan dengan menggunakan variabel THD arus adalah 100\% dan tidak ada pengaruh yang disebabkan oleh variabel-variabel lain diluar model ini.

Dari tabel 4.4 dapat menghasilkan persamaan sebagai berikut:

$$
\begin{aligned}
& Y=b_{0}-b_{1} x \\
& Y=38,151-0,246 x
\end{aligned}
$$


Dari persamaan diatas dapat diartikan setiap kenaikan satu satuan nilai THD arus maka kapasitas daya transformator naik sebesar 0,246.

\subsubsection{Analisis pengaruh tingginya suhu terhadap load losses yang terjadi pada transformator}

Tabel 4.2 Data pengaruh suhu terhadap load losses

\begin{tabular}{|c|c|c|c|}
\hline $\begin{array}{c}\text { Waktu beban } \\
\text { puncak }\end{array}$ & $\begin{array}{c}\text { Loa } \\
d \\
(\%)\end{array}$ & $\begin{array}{c}\text { Suh } \\
\mathrm{u} \\
\left({ }^{\circ} \mathrm{C}\right)\end{array}$ & $\begin{array}{c}\text { Load } \\
\text { Losses } \\
\text { (watt) }\end{array}$ \\
\hline $\begin{array}{c}14 / 11 / 2014 \\
19: 05\end{array}$ & $\begin{array}{c}93, \\
24\end{array}$ & 41 & 913,04 \\
\hline $\begin{array}{c}15 / 11 / 2014 \\
20: 17\end{array}$ & $\begin{array}{c}91, \\
63\end{array}$ & 46 & 896,74 \\
\hline $\begin{array}{c}16 / 11 / 2014 \\
18: 57\end{array}$ & $\begin{array}{c}90, \\
51\end{array}$ & 42 & 863,27 \\
\hline $\begin{array}{c}17 / 11 / 2014 \\
19: 27\end{array}$ & $\begin{array}{c}88, \\
75\end{array}$ & 38 & 818,83 \\
\hline $\begin{array}{c}18 / 11 / 2014 \\
18: 59\end{array}$ & $\begin{array}{c}75, \\
90\end{array}$ & 43 & 609,12 \\
\hline
\end{tabular}

Berdasarkan tabel 4.2 bahwa suhu tidak diikuti oleh kenaikan load losses pada pada tranformator. Suhu terbesar $47 \%$ dan dalam waktu yang tidak sama load losses terbesar 1050 watt.

\section{Pengaruh Suhu Terhadap Load Losses}

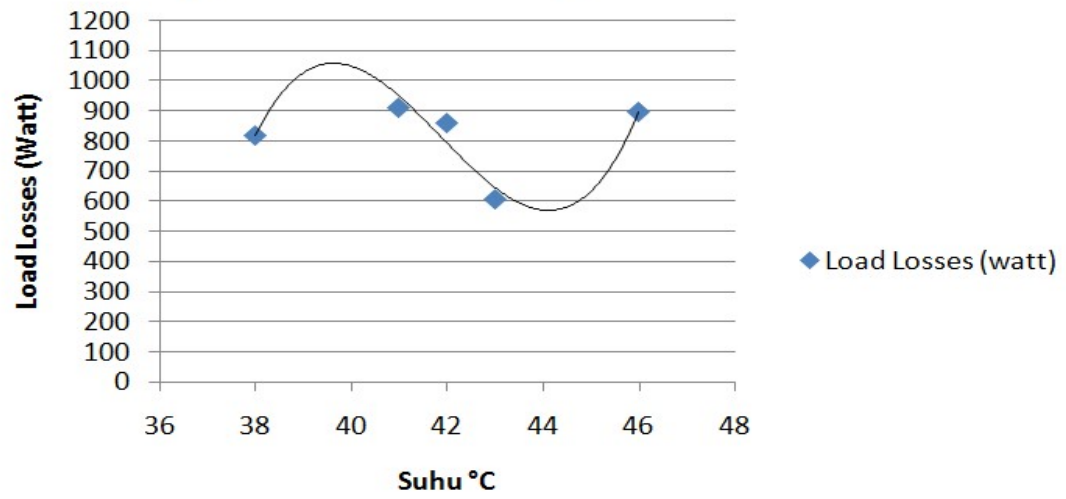

Gambar 4.4 Pengaruh Suhu Terhadap Load Losses

Berdasarkan Gambar 4.4 bahwa kenaikan suhu tidak mempengaruhi besarnya load losses transformator. Jadi semakin besar beban tidak akan langsung menyebabkan kenaikan suhu.

\subsubsection{Uji koefisien determinasi $\left(R^{2}\right)$}

Koefisien determinasi $\left(\mathrm{R}^{2}\right)$ suhu sebesar 0,876 yang berarti bahwa pengaruh suhu arus terhadap load losses $87 \%$ sedangkan sisanya $17 \%$ dipengaruhi oleh faktor lain. Dengan kata lain, variabel suhu yang dapat diterangkan dengan menggunakan 
variabel suhu adalah $87 \%$ sedangkan pengaruh sebesar $17 \%$ disebabkan oleh variabel-variabel lain diluar model ini.

Dari gambar 4.4 dapat menghasilkan persamaan sebagai berikut:

$$
\begin{gathered}
Y=a x^{3}+b x^{2}+c x+d \\
Y=10,78 x^{3}-1354, x^{2}+56562 x-78426
\end{gathered}
$$

\subsection{Analisis pengaruh ketidakseimbangan beban terhadap besarnya arus netral yang terjadi pada transformator}

Tabel 4.3 Arus netral terhadap kapasitas daya transformator

\begin{tabular}{|l|c|c|c|}
\hline \multicolumn{1}{|c|}{$\begin{array}{c}\text { Waktu beban } \\
\text { puncak }\end{array}$} & $\begin{array}{c}\text { Load } \\
(\%)\end{array}$ & $\begin{array}{c}\text { Arus } \\
\text { Netral } \\
(\mathrm{A})\end{array}$ & $\begin{array}{c}\text { Ketidak } \\
\text { seimbangan \% }\end{array}$ \\
\hline $\begin{array}{l}14 / 11 / 2014 \\
19: 05\end{array}$ & 93,24 & 64 & 31,37 \\
\hline $\begin{array}{l}15 / 11 / 2014 \\
20: 17\end{array}$ & 91,63 & 72 & 37,33 \\
\hline $\begin{array}{l}16 / 11 / 2014 \\
18: 57\end{array}$ & 90,51 & 60 & 29,33 \\
\hline $\begin{array}{l}17 / 11 / 2014 \\
19: 27\end{array}$ & 88,75 & 68 & 37,5 \\
\hline $\begin{array}{l}18 / 11 / 2014 \\
18: 59\end{array}$ & 75,9 & 60 & 35,46 \\
\hline
\end{tabular}

Berdasarkan gambar 4.3 bahwa ketidakseimbangan beban diikuti oleh kenaikan arus netral pada pada tranformator. Ketidakseimbangan terbesar $37 \%$ dan dalam waktu yang sama kenaikan arus netral terbesar 72 Amper.

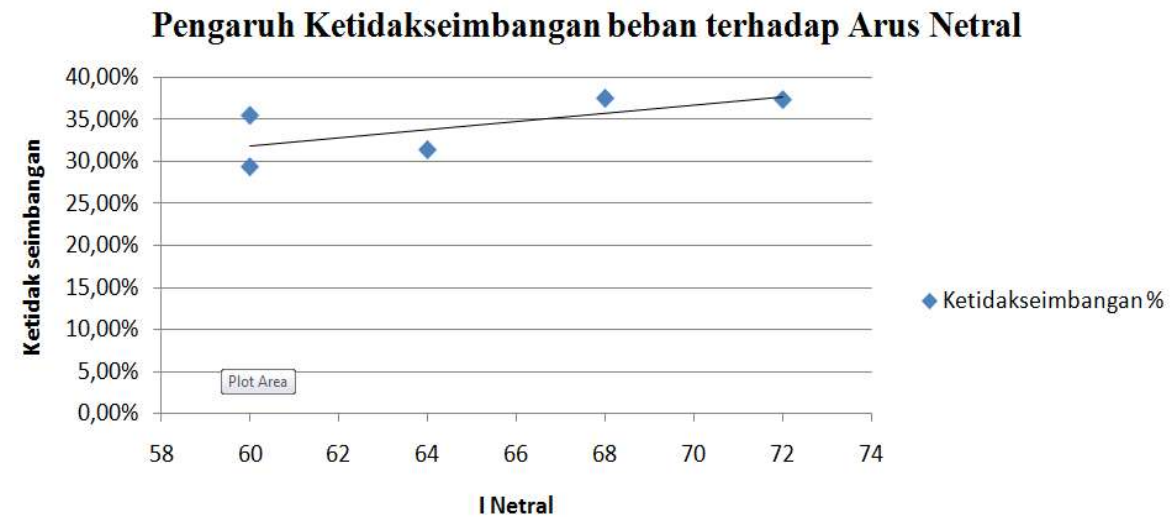

Gambar 4.5 Pengaruh ketidakseimbangan beban terhadap besarnya arus netral yang terjadi pada transformator

Berdasarkan Gambar 4.5 menunjukkan bahwa semakin besar ketidakseimbangan beban mengakibatkan semakin besar arus netral. 


\subsubsection{Uji koefisien determinasi $\left(R^{2}\right)$}

Tabel 4.4 koefisiensi determinasi pengaruh ketidakseimbangan arus terhadap arus netral.

Coefficients $^{\mathrm{a}}$

\begin{tabular}{|c|c|c|c|c|c|c|c|c|c|}
\hline \multirow[b]{2}{*}{ Model } & & \multicolumn{2}{|c|}{ Unstandardized Coefficients } & \multirow{2}{*}{\begin{tabular}{|c|}
$\begin{array}{c}\text { Standardized } \\
\text { Coefficients }\end{array}$ \\
Beta \\
\end{tabular}} & \multirow[b]{2}{*}{$t$} & \multirow[b]{2}{*}{ Sig. } & \multicolumn{3}{|c|}{ Correlations } \\
\hline & & $B$ & Std. Error & & & & Zero-order & Partial & Part \\
\hline 1 & (Constant) & 31.416 & 20.450 & & 1.536 & .222 & & & \\
\hline & Ketidakseimbangan & .976 & .595 & .688 & 1.640 & .200 & .688 & .688 & .688 \\
\hline
\end{tabular}

a. Dependent Variable: IN

Koefisien determinasi $\left(\mathrm{R}^{2}\right)$ ketidakseimbangan arus 0,473 yang berarti bahwa pengaruh ketidakseimbangan arus terhadap arus netral 47\% sedangkan sisanya $53 \%$ dipengaruhi oleh faktor lain. Dengan kata lain, variabel arus netral yang dapat diterangkan dengan menggunakan variabel ketidakseimbangan adalah 47\% sedangkan pengaruh sebesar 53\% disebabkan oleh variabel-variabel lain diluar model ini.

Dari tabel 4.4 dapat diperoleh persamaan sebagai berikut:

$$
\begin{gathered}
Y=b_{0}+b_{1} x \\
Y=31,416+0,976 x
\end{gathered}
$$

Dari persamaan diatas dapat diartikan setiap kenaikan satu satuan nilai ketidakseimbangan maka arus netral akan naik sebesar 0,976.

\section{KESIMPULAN}

Berdasarkan hasil pembahasan dan analisis, maka dapat disimpulkan sebagai berikut:

1. Software ini dapat menampilkan menu analisis beban puncak harian, analisis suhu terhadap loses, analisis pengaruh keseimbangan beban terhadap arus netral, analisis pengaruh total harmonic distorsi arus terhadap kapasitas transformator, dan grafik-grafik hasil analisis tersebut.

2. Semakin besar nilai THD arus maka akan semakin besar penurunan kapasitas daya transformator.

3. Load losses tidak hanya dipengaruhi oleh suhu saja. Karena suhu lingkungan juga mempengaruhinya.

4. Ketidakseimbangan beban mengakibatkan besarnya arus netral. Sehingga untuk mengurangi besarnya arus netral pada transformator dapat dilakukan penyeimbangan antar fasa.

\section{DAFTAR RUJUKAN}

[1] G. A. Sari, M. Dhofir, and U. Wibawa, "Analisis Kinerja Transformator Daya Dengan Metode Markov," J. Mhs. TEUB, vol. 4, no. 3, 2016.

[2] "IEEE Recommended Practice for Emergency and Standby Power Systems for Industrial and Commercial Applications," IEEE. 
[3] J. Sentosa Setiadji, T. Machmudsyah, and Y. Isnanto, "Pengaruh Ketidakseimbangan Beban Terhadap Arus Netral dan Losses pada Trafo Distribusi," J. Tek. Elektro, vol. 7, no. 2, Jan. 2008.

[4] I. Jayanti, "Analisis Pengaruh Harmonisa Terhadap Penurunan Kapasitas Transformator 3 Fasa Pt Ajinomoto Mojokerto Factory," Sarjana, Universitas Brawijaya, 2012. 